\title{
BITE FORCE EVALUATION IN SUBJECTS WITH CLEFT LIP AND PALATE
}

\author{
Carla Renata SIPERT ${ }^{1}$, Ana Claudia Martins SAMPAIO ${ }^{2}$, Inge Elly Kiemle TRINDADE ${ }^{3}$, Alceu Sérgio TRINDADE JUNIOR ${ }^{3}$
}

\author{
1- DDS, MSc, Graduate Student, Department of Biological Sciences, Bauru School of Dentistry, University of São Paulo, Bauru, SP, Brazil. \\ 2- MSc, PhD, Hospital for Rehabilitation of Craniofacial Anomalies, University of São Paulo, Bauru, SP, Brazil. \\ 3- MSc, PhD, Full Professor, Department of Biological Sciences, Bauru School of Dentistry, University of São Paulo, Bauru, SP, Brazil.
}

Corresponding addres: Prof. Dr. Alceu Sérgio Trindade Júnior - Al. Octavio Pinheiro Brisolla, n. 9-75 - 17012-901 - Bauru - SP - Brasil - Phone: +5514-3235-8282 - Fax: +55-14-3235-8000 - e-mail: atrind@usp.br.

Received: April 18, 2008 - Accepted: August 30, 2008

\begin{abstract}
$T_{\text {r }}$

he purpose of this study was to evaluate the masticatory function of subjects with cleft lip and palate by analyzing the bite force developed by these individuals. Bite force was evaluated in a group of 27 individuals with repaired unilateral cleft lip and palate (14 males and 13 females - aged 18-26 years) and compared to the data achieved from a group of 20 noncleft subjects (10 males and 10 females - aged 18-26 years). Measurement was achieved on three positions within the dental arch (incisors, right molars and left molars), three times at each position considering the highest value for each one. Statistical analysis was performed by ANOVA and Mann-Whitney test $(\alpha=5 \%)$. There was a significant deficit in bite force in male individuals with cleft lip and palate compared to the male control group ( $\mathrm{p}=0.02, \mathrm{p}=0.004, \mathrm{p}=0.003$ for incisors, right and left molars, respectively). For the female group, the difference was not statistically significant $(\mathrm{p}=0.79, \mathrm{p}=0.06, \mathrm{p}=0.47)$. In the group of individuals with clefts, $92.6 \%$ were under orthodontic treatment, which could be a reason for the present findings, since it can decrease the bite force more remarkably in males than in females. In conclusion, the bite force is significantly reduced in men when comparing the cleft group to the noncleft group. In females, this reduction was not significant in the same way. However, the main reason for this reduction and for the different behavior between genders should be further investigated.
\end{abstract}

Key words: Bite force. Cleft lip. Cleft palate. Orthodontics.

\section{INTRODUCTION}

The treatment of patients with cleft lip and palate involves a multidisciplinary team approach including pediatrics, oral and maxillofacial surgery, otolaryngology, prosthodontics, speech therapy, genetics, and others. Rehabilitation is initiated in the first months of life and is continued until adult age. Because of its complexity, the treatment of cleft lip and palate requires knowledge of the alterations of the stomatognathic system of these subjects for complete rehabilitation ${ }^{12}$.

The bite force or masticatory function yielded by masticatory muscles influences not only the occlusal variations and dental arch form, but also the mandibular shape and structure $^{23}$. Many studies reported in the literature use the bite force as a clinical indicator of masticatory performance ${ }^{19}$. This parameter is correlated with craniofacial morphology $9,11,23,24$, gender $^{18}$, age ${ }^{7}$, temporomandibular disorders (TMD) $)^{6,8,14,16}$ and also with status, number and tooth mobility ${ }^{10}$. The same relationship is found in patients submitted to orthodontic treatment ${ }^{3,19,20,25}$, orthognathic surgery ${ }^{15,21}$, etc. However, there is no information on the bite force in patients with cleft lip and palate, a valid resource for evaluation of the neuromuscular function in these subjects. The aim of the present investigation was to quantify the bite force that patients with cleft lip and palate are able to develop, comparing these data to the values found for noncleft individuals.

\section{MATERIAL AND METHODS}

\section{Population}

This study was conducted on 27 patients (14 males and 13 females; age: 18 to 26 years) with repaired unilateral cleft lip and palate under treatment at the Hospital for Rehabilitation of Craniofacial Anomalies - USP, Bauru, SP, Brazil. One of the subjects had not been submitted to orthodontic treatment, and 2 females and 2 males had already completed it. The others were under orthodontic treatment and 8 subjects of each group wore fixed appliances at the time of measurements. None of the patients had undergone orthognathic surgery less than one year before measurement. At examination for $\mathrm{TMD}^{2}$, patients' symptoms varied from not existing to mild. Fourteen patients presented unstable occlusion. In the control group, 20 noncleft subjects ( 10 males and 10 females) also aged 18 


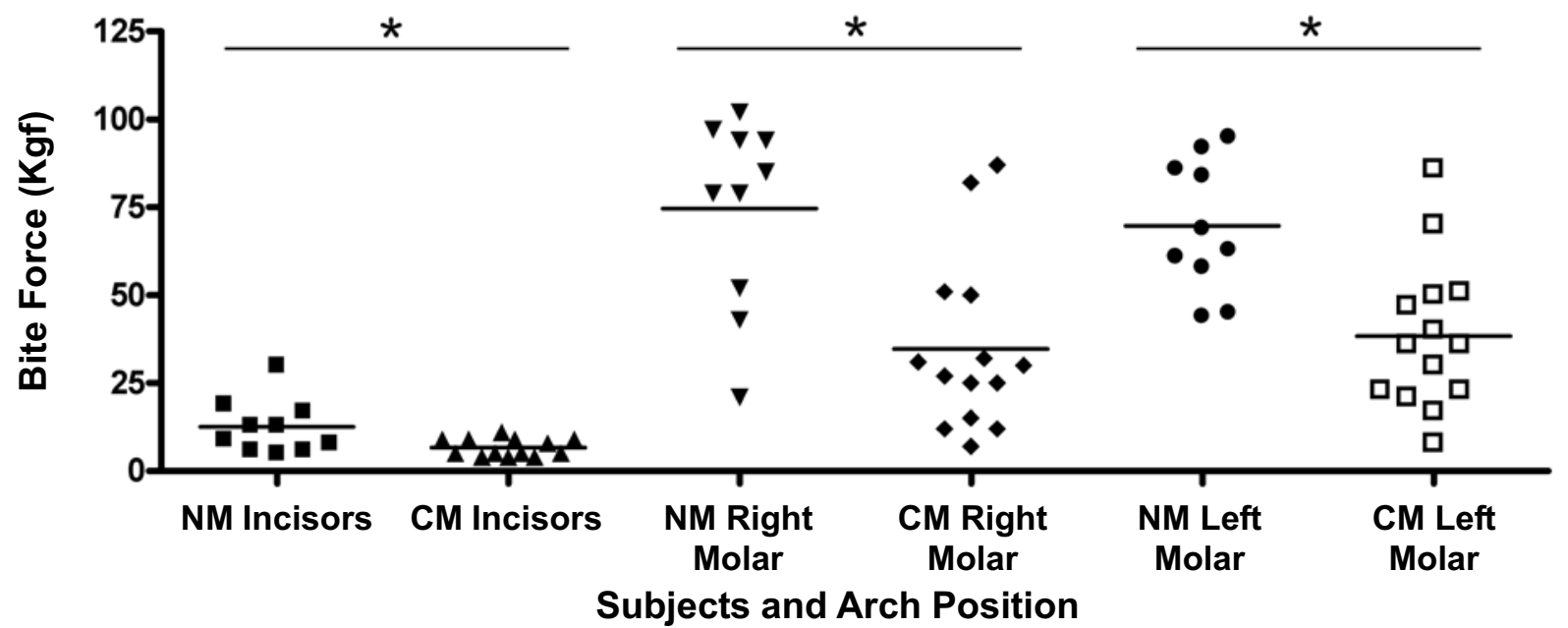

FIGURE 1- Maximum isometric bite force in the male group: Noncleft male subjects (NM) and repaired cleft lip and palate male patients (CM) (kgf). Data representative of values performed by each subject. Statistically significant difference observed between NM and CM subjects $\left(^{*}\right)$

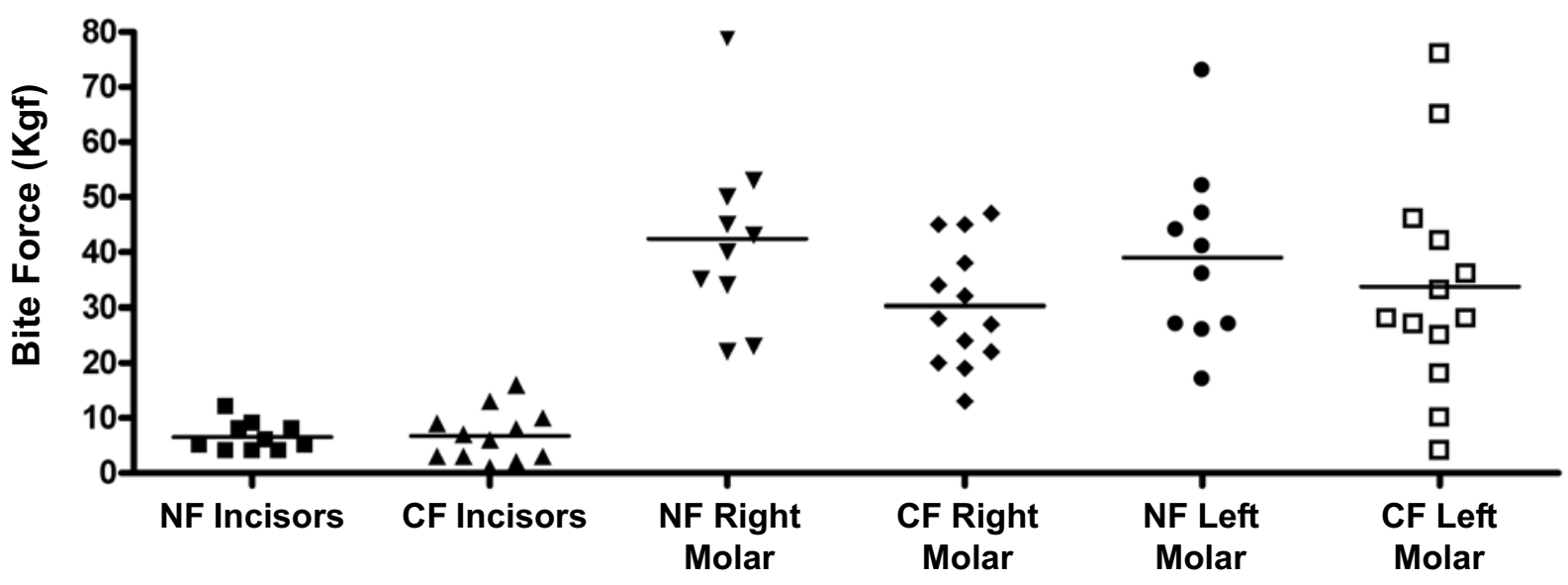

Subjects and Arch Position

FIGURE 2- Maximum isometric bite force in the female group: Noncleft Female subjects (NF) and repaired cleft lip and palate female patients (CF) (kgf). Data representative of values performed by each subject. No statistically significant difference was observed between NF and CF subjects

to 26 years were evaluated. This sample included only individuals without any signs and symptoms of TMD with no need of prosthetic or orthodontic treatment.

Prior to patient enrollment, the research protocol was reviewed and approved by the Hospital's Research Ethics Committee and all participants signed a written informed consent form.

\section{Bite force measurement}

A gnathodynamometer (cell charge type with a strain gauge sensor) (KFC-D16-11 Kyowa Electronic Instruments CO., Tokyo, Japan) was used for measurement of maximum isometric bite force. This equipment consists of a $10 \mathrm{~mm}$ high $\mathrm{x} 10 \mathrm{~mm}$ diameter stainless steel cylinder enclosing two strain gauge sensors (Figure 3).

Measurements were taken with the patient comfortably seated in a dental chair. The stainless steel cylinder was wrapped by a plastic shield previously disinfected with $77^{\circ} \mathrm{GL}$ alcohol, changed for each patient. The maximum isometric bite force was quantified (in kgf) in the molar region bilaterally and in the anterior region at points where the subject felt safer to develop the maximum strength (Figure 4). Measurement was accomplished three times at each position, with a $30-\mathrm{s}$ interval between measurements to avoid muscular fatigue. The highest value of each position was considered for analysis.

\section{Statistical analisis}

Comparison was made among the values developed by cleft and normal subjects by ANOVA. Comparisons for subjects of the same gender at each dental arch position were performed through Mann-Whitney test. Significance level was set at $\mathrm{p}<0.05$.

\section{RESULTS}

The results obtained from bite force measurement are presented in Figures 1 and 2. 


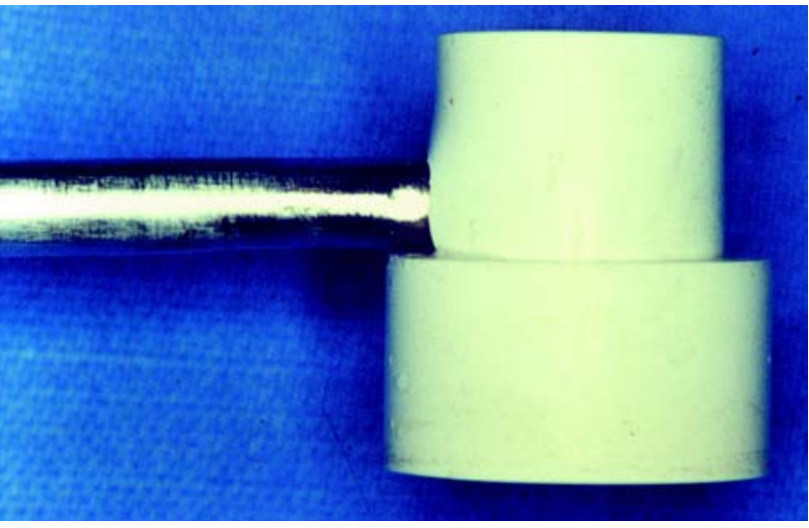

FIGURE 3- Gnathodynamometer used for bite force measurement. This equipment consists of a $10 \mathrm{~mm}$ high $\mathrm{x}$ $10 \mathrm{~mm}$ diameter stainless steel cylinder enclosing two strain gauge sensors

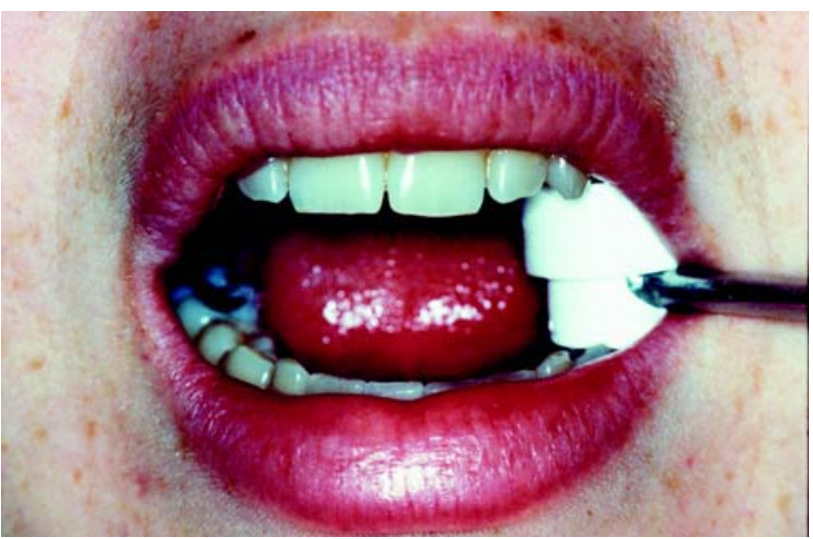

FIGURE 4- Bite force sensor at measurement position. The maximum isometric bite force was quantified at points where the subject felt safer to develop the maximum strength

No group showed statistically significant difference between $(p>0.05)$ bite force values at the right and left sides, while differences were found between anterior and posterior regions, in agreement with the current literature ${ }^{6,17,21,22}$. In cleft lip and palate subjects, no significant differences ( $>0.05)$ were found between the cleft and noncleft sides (data not shown).

Data analysis of the four groups by ANOVA showed interaction between gender and bite force performance. This analysis implies that the comparison between maximum isometric bite force depends on gender. Considering that, a bite force deficit was observed in the cleft group compared to the noncleft one through Mann-Whitney test. However, statistically significant difference was observed only comparing male subjects with $p$ values of $0.02,0.004$ and 0.003 for incisors, right molars and left molars, respectively (Figure 1). Differences between female groups were also found, however without statistically significant differences $(\mathrm{p}=0.79, \mathrm{p}=0.06$ and $\mathrm{p}=0.47$, for incisors, right molars and left molars, respectively) (Figure 2). The great variability between subjects at the same group impairs the observation of significant differences.

\section{DISCUSSION}

Bite force evaluation is well recognized in the literature as a clinical indicator of masticatory performance. However, the sensors employed for bite force measurement, such as those used in the present study, constitute an apparatus that act by interposition between superior and inferior dental arches. Although the masticatory forces are improved from 10 to $20 \mathrm{~mm}$ of mouth opening, there is no possibility to evaluate this parameter with appliances that do not introduce arch interposition.

The present study was designed to estimate the functional condition of the masticatory system of surgically repaired cleft lip and palate subjects by maximum isometric bite force. This parameter in cleft subjects was reduced compared to noncleft male subjects. On the other hand, the difference found for the female gender was not statistically significant. In a group of noncleft subjects, the difference between males and females has been shown to be significant, with a reduction for females ${ }^{3,7,10,18,19,21}$. For this reason, the results obtained for males and females were considered separately.

Among the patients, 3 males and 3 females had undergone orthognathic surgery with a minimum postsurgical period of 1 year. This period is considered enough to restore the occlusal forces ${ }^{15,21}$. Missing teeth were significant only in 2 patients in cleft area, and thus measurements were not taken in the anterior region for these patients. The TMD varied from not existing to mild, and none of the subjects had relevant signs or symptoms of TMD. These data exclude the possibility of bite force reduction caused by orthognathic surgery postoperatively ${ }^{15,21}$, $\mathrm{TMD}^{6,8,14,16}$ or missing teeth ${ }^{10}$.

Among the patients of this sample, 2 individuals of each group were not under orthodontic treatment and 8 individuals of each group wore fixed appliances. Included in factors that affect the stomatognathic function, orthodontics has been mentioned as an important reason for reduction in bite force values in several studies ${ }^{3,4,20,21,25}$. The reasons for this deficit are still not completely known, but pain has been reported as the main cause for bite force reduction in these cases ${ }^{3,20,21}$. The pain from periodontal tissue alteration caused by the force and increased by the inflammatory response is transmitted to the central nervous system and a protective stimulus is sent back, which inhibits the action of jaw closing muscles, thereby avoiding additional damage to periodontal tissues ${ }^{20}$. Studies describe the pain as the most unpleasant aspect reported by the patients ${ }^{1,13}$, being one of the major causes of discontinuance of treatment ${ }^{5}$. However, in the present study, only the bite force reduction observed for male cleft subjects compared to male noncleft subjects was significant. The same phenomenon was previously reported by Throckmorton, et al. ${ }^{21}$ (1996), who observed a greater bite force deficit for males than for females submitted to orthodontic treatment. These data suggest that bite force reduction in patients with unilateral cleft lip and palate is more related to orthodontic treatment than to the presence of the cleft, especially because no differences were observed between the cleft and noncleft sides when analyzing the force 
performed by these subjects. However, this hypothesis could not be confirmed because there is no possibility to evaluate bite force of cleft lip and palate subjects not wearing orthodontic appliances due to the long oral rehabilitation treatment that these patients should undergo.

\section{CONCLUSION}

Based on the findings of this investigation, it may be concluded that patients with repaired cleft lip and palate have a decrease in maximum isometric bite force that is significant only in male subjects. The reasons for these findings are not clearly understood and further studies must be performed to determine whether this reduction is related or not to the presence of the cleft per se.

\section{ACKNOWLEDGEMENTS}

The authors would like to acknowledge MSc. Marcel F.L. Taga for his excellent statistical assistance. This study was performed with a scholarship grant from PIBIC/CNPq (Brazilian Federal Government).

\section{REFERENCES}

1- Brown DF, Moerenhout RG. The pain experience and psychological adjustment to orthodontic treatment of preadolescents, adolescents, and adults. Am J Orthod Dentofac Orthop. 1991;100(4):349-56.

2- Dawson P. Evaluation, diagnosis and treatment of occlusal problems. 2nd ed. Saint Louis: Mosby; 1988.

3- Dean JS, Throckmorton GS, Ellis E 3rd, Sinn DP. A preliminary study of maximum voluntary bite force and jaw muscle efficiency in preorthognathic surgery patients. J Oral Maxillofac Surg. 1992;50(12):12848 .

4- Ellis E 3rd, Throckmorton GS, Sinn DP. Bite forces before and after surgical correction of mandibular prognathism. J Oral Maxillofac Surg. 1996;54(2):176-81

5- Haynes S. Discontinuation of orthodontic treatment relative to patient age. J Dent. 1974;2(4):138-42.

6- Helkimo E, Ingervall B. Bite force and functional state of the masticatory system in young men. Swed Dent J. 1978;2(5):167-75.

7- Kiliaridis S, Kjellberg H, Wenneberg B, Engstrom C. The relationship between maximal bite force, bite force endurance, and facial morphology during growth. A cross-sectional study. Acta Odontol Scand. $1993 ; 51(5): 323-31$

8- Kogawa EM, Calderon PS, Lauris JR, Araujo CR, Conti PC. Evaluation of maximal bite force in temporomandibular disorders patients. J Oral Rehabil. 2006;33(8):559-65.

9- Miralles R, Hevia R, Contreras L, Carvajal R, Bull R, Manns A. Patterns of electromyographic activity in subjects with different skeletal facial types. Angle Orthod. 1991;61(4):277-84.
10- Miyaura K, Matsuka Y, Morita M, Yamashita A, Watanabe T. Comparison of biting forces in different age and sex groups: a study of biting efficiency with mobile and non-mobile teeth. J Oral Rehabil. $1999 ; 26(3): 223-7$

11- Moriya Y, Tuchida K, Moriya Y, Sawada T, Koga J, Sato J, et al. The influence of craniofacial form on bite force and EMG activity of masticatory muscles. VIII-1. Bite force of complete denture wearers. J Oral Sci. 1999;41(1):19-27.

12- Neville B, Damm D, Allen C, Bouquot J. Oral \& Maxillofacial Pathology: Philadelphia, W.B. Saunders; 1995.

13- Oliver RG, Knapman YM. Attitudes to orthodontic treatment. Br J Orthod. 1985;12(4):179-88.

14- Pizolato RA, Gaviao MB, Berretin-Felix G, Sampaio AC, Trindade AS Jr. Maximal bite force in young adults with temporomandibular disorders and bruxism. Braz Oral Res. 2007;21(3):278-83.

15- Proffit WR, Turvey TA, Fields HW, Phillips C. The effect of orthognathic surgery on occlusal force. J Oral Maxillofac Surg. 1989;47(5):457-63

16- Sato S, Ohta M, Sawatari M, Kawamura H, Motegi K. Occlusal contact area, occlusal pressure, bite force, and masticatory efficiency in patients with anterior disc displacement of the temporomandibular joint. J Oral Rehabil. 1999;26(11):906-11.

17- Shinogaya T, Sodeyama A, Matsumoto M. Bite force and occlusal load distribution in normal complete dentitions of young adults. Eur $\mathrm{J}$ Prosthodont Restor Dent. 1999;7(2):65-70.

18- Tate GS, Throckmorton GS, Ellis E 3rd, Sinn DP. Masticatory performance, muscle activity, and occlusal force in preorthognathic surgery patients. J Oral Maxillofac Surg. 1994;52(5):476-81; discussion 482.

19- Tate GS, Throckmorton GS, Ellis E 3rd, Sinn DP, Blackwood DJ. Estimated masticatory forces in patients before orthognathic surgery. J Oral Maxillofac Surg. 1994;52(2):130-6; discussion 136-7.

20- Thomas GP, Throckmorton GS, Ellis E 3rd, Sinn DP. The effects of orthodontic treatment on isometric bite forces and mandibular motion in patients before orthognathic surgery. J Oral Maxillofac Surg. 1995;53(6):673-8; discussion 678-9

21- Throckmorton GS, Buschang PH, Ellis E 3rd. Improvement of maximum occlusal forces after orthognathic surgery. J Oral Maxillofac Surg. 1996;54(9):1080-6

22- Tortopidis D, Lyons MF, Baxendale RH. Bite force, endurance and masseter muscle fatigue in healthy edentulous subjects and those with TMD. J Oral Rehabil. 1999;26(4):321-8.

23- Tsunori M, Mashita M, Kasai K. Relationship between facial types and tooth and bone characteristics of the mandible obtained by $\mathrm{CT}$ scanning. Angle Orthod. 1998;68(6):557-62.

24- van Eijden TM. Three-dimensional analyses of human bite-force magnitude and moment. Arch Oral Biol. 1991;36(7):535-9.

25- Winocur E, Davidov I, Gazit E, Brosh T, Vardimon AD. Centric slide, bite force and muscle tenderness changes over 6 months following fixed orthodontic treatment. Angle Orthod. 2007;77(2):254-9. 